\title{
Impacts of growth temperature, water deficit and heatwaves on carbon assimilation and growth of cotton plants (Gossypium hirsutum L.)
}

\author{
Ximeng $\mathrm{Li}^{1}$, Wen $\mathrm{Shi}^{2}$, Katie Broughton ${ }^{2}$, Renee $\mathrm{Smith}^{2}$, Robert Sharwood ${ }^{3}$, Paxton \\ Payton $^{4}$, Michael Bange ${ }^{2}$, and David Tissue ${ }^{5}$ \\ ${ }^{1}$ Western Sydney University Hawkesbury Institute for the Environment \\ ${ }^{2}$ Affiliation not available \\ ${ }^{3}$ Australian National University \\ ${ }^{4}$ USDA-ARS Plains Area \\ ${ }^{5}$ Western Sydney University
}

June 1, 2020

\begin{abstract}
Assessing the impacts of climate change on cotton is essential for maintaining a stable fibre production in the future. Here, cotton plants (Gossypium hirsutum L.) were raised under two temperature regimes (28/18 oC and 32/22 oC) and their corresponding nocturnal warming $(+4 \mathrm{oC})$ scenarios (i.e. $28 / 22 \mathrm{oC}$ and $32 / 26 \mathrm{oC}$ ), and subsequently exposed to two water (Well-watered and Water deficit) and heatwave treatments (Control and Heatwave). Warmer day growth temperatures increased growth rate and leaf carbon gain, but decreased aboveground biomass. Water treatment independently or interactive affected leaf physiology and yield with growth temperature, but these impacts were generally small. Nocturnal warming did not strongly alter leaf carbon balance and its impacts on biomass were thermal regime specific. Warm temperature preconditioning did not ameliorate the negative effects of heatwave on carbon gain, but biomass accumulation was less affected due to high resilience. Overall, both short- and long-term elevated daytime temperature decrease cotton yield, while nocturnal warming has limited capacity to buffer that impact. Moderate water deficit will not strongly reduce carbon gain and growth. Findings of this study improve the knowledge regarding the response of cotton plants to climate change and underscore the complexity of plant response to multiple environmental factors.
\end{abstract}

\section{Introduction}

Global cotton farming is increasingly challenged by rapid changes in climate (Reddy, Hodges, \& McKinion, 1997; Williams et al., 2015). Cotton plants (Gossypium hirsutum L.) are known to tolerate a variety of abiotic stresses, yet climate anomalies and extremes can place cotton at greater risk of yield loss (Schlenker \& Roberts, 2009; Snider, Oosterhuis, Skulman, \& Kawakami, 2009; Ullah, Sun, Yang, \& Zhang, 2017). Projections of global climate issued by IPCC indicate a $2^{\circ} \mathrm{C}$ to $4^{\circ} \mathrm{C}$ rise in global average temperature by 2050 across different $\mathrm{CO}_{2}$ emission scenarios (Pachauri et al., 2014), accompanied by increased intensity and frequency of drought stress and heatwaves in many arid regions worldwide (Dai, 2013; Perkins, Alexander, \& Nairn, 2012). These climate scenarios will most likely generate environmental conditions beyond the optimal range for cotton growth, potentially resulting in more severe yield reduction in the near future unless management strategies are developed to improve crop adaptation. A better understanding of the potential impacts of rising temperatures and drought on cotton growth will provide valuable information guiding agronomic management required to maintain stable fibre production in the future. 
Water availability is one of the most limiting factors constraining cotton productivity, especially in arid and semi-arid regions where water demand often exceeds irrigation capacity and significant land areas are often grown under rain-fed conditions (Bange, Carberry, Marshall, \& Milroy, 2005; Ullah et al., 2017). During periods of water deficit stress, stomata typically close to minimize transpiration, which comes at the expense of carbon gain, given that water and $\mathrm{CO}_{2}$ exchange share the same pathway at the leaf level (Flexas, Bota, Loreto, Cornic, \& Sharkey, 2004). Protracted drought stress can also affect photosynthetic electron transport, which may cause cell damage and lead to chronic down-regulation of photosynthesis (Impa, Nadaradjan, \& Jagadish, 2012; Kitao \& Lei, 2007; Sekmen, Ozgur, Uzilday, \& Turkan, 2014). The response of cotton photosynthesis to water deficit has been examined extensively (Broughton et al., 2017; Chastain et al., 2014; Snider et al., 2015; Yi et al., 2016). It is known that leaf stomata of cotton are highly sensitive to water deficit, attaining complete closure during the early phase of drought stress (Li, Smith, Choat, \& Tissue, 2019), which enables cotton to cope with short-term, mild drought without strongly affecting biomass production. However, prolonged drought can greatly compromise carbon gain, with cascading negative consequences on growth and yield (Broughton et al., 2017; Wang et al., 2016).

Temperature plays a major role in regulating plant performance due to high thermal sensitivity of many enzymatic reactions involved in carbon gain and growth regulation (Long \& Ort 2010). Temperature per sehas been demonstrated to be a chief regulator of cotton growth (Pettigrew, 2008; Reddy, Hodges, \& Reddy, 1992; Reddy, Baker, \& Hodges, 1991). Moreover, elevated temperature can increase the level of atmospheric drought (i.e. high VPD), which will aggravate the negative effects of drought (Broughton et al., 2017). Early findings indicate that increased average daily temperatures at the beginning and the end of the growth season can promote biomass accumulation, yet long-term exposure to sub-optimal growth temperatures will result in substantial yield loss (Bange, 2007; Pettigrew, 2008; Reddy, Baker, et al., 1991; Reddy, Reddy, \& Baker, 1991). It has been shown that the growth of cotton is maximized within the temperature range of $20^{\sim} 30^{\circ} \mathrm{C}$ (Reddy, Hodges, et al., 1992; Reddy, Baker, et al., 1991), while the optimum thermal range for enzymatic activity, germination, flowering and lint production is $28 \pm 3^{\circ} \mathrm{C}$ (Burke \& Wanjura, 2010); when growth temperature exceeds $35^{\circ} \mathrm{C}$, rates of photosynthesis decline due to declining Rubisco activity as a result of deactivation and increased respiration (Loka \& Oosterhuis, 2010; Sharwood, 2017). The thermal operating range of plants is dependent on physiological acclimation. For example, the temperature dependence of photosynthesis can exhibit phenotypic plasticity in response to growth temperature, such that warm-grown plants typically have higher optimum temperature of photosynthesis $\left(\mathrm{T}_{\mathrm{opt}}\right)$, thus enabling plants to maintain positive carbon gain under new thermal regimes (Way \& Yamori, 2014; Yamori, Hikosaka, \& Way, 2014). Rapid thermal adjustment in photosynthesis is of fundamental importance to cotton growth and yield, given that elevation in temperatures is prevalent in regions where cotton is often planted (Broughton et al., 2020; Singh, Prasad, Sunita, Giri, \& Reddy, 2007).

Projections of climate change suggest a larger increase in night-time temperature (Pachauri et al., 2014), which can have distinct effects on crop physiology and productivity compared to elevated daytime temperature (Izquierdo, Aguirrezábal, Andrade, \& Pereyra, 2002; Mohammed \& Tarpley, 2009; Prasad, Pisipati, Ristic, Bukovnik, \& Fritz, 2008; Prasad \& Djanaguiraman, 2011; Wolfe-Bellin, He, \& Bazzaz, 2006). Respiration is thermally sensitive and dominates the carbon flux in darkness. Nocturnal warming may promote carbon loss, leading to decreased carbohydrate availability, which are key determinants of fruit yield and quality (Loka \& Oosterhuis, 2010; Pettigrew, 2001, 2008). The carbohydrate shortage related plant growth anomalies can be further intensified by nocturnal warming related down-regulation of photosynthesis (Reddy, Baker, et al., 1991; Sinsawat, Leipner, Stamp, \& Fracheboud, 2004). Moreover, elevated night-time temperature can cause early abscission of reproductive structures, further decreasing reproductive dry matter (Soliz, Oosterhuis, Coker, \& Brown, 2008). Reduced yield caused by elevated night temperature has been observed in many crops, especially for species characterized by higher respiratory thermal sensitivity, including cotton (Gipson \& Joham, 1968; Mohammed \& Tarpley, 2009; Prasad et al., 2008; Soliz et al., 2008).

From a physiological perspective, short-term pulses of high temperature can push plants beyond their thermal thresholds, resulting in the sudden collapse of many metabolic processes (Zhu et al., 2018). High temperature impairs the photosynthetic apparatus by disrupting photosynthetic pigments, inhibiting activity of photo- 
system II and deactivating various enzymes involved in photosynthetic carbon reactions (Chavan, Duursma, Tausz, \& Ghannoum, 2019; Law, Crafts-Brandner, \& Salvucci, 2001). Furthermore, heatwaves can increase water loss without improving photosynthesis, which will exacerbate the impairments of drought stress on carbon gain (Najeeb, Sarwar, Atwell, Bange, \& Tan, 2017). For cotton plants, reduced photosynthesis, growth, fruit production and fibre quality have been observed in plants subjected to short-term increased temperature (Carmo-Silva et al., 2012; Snider et al., 2009). It is proposed that the response to heatwaves can be modified by plant thermal history, such that warm grown plants might be less affected by heat stress compared to cool-grown counterparts (Haldimann \& Feller, 2005; Kurek et al., 2007; Larkindale \& Vierling, 2008; Salvucci \& Crafts-Brandner, 2004). Yet, it is unclear if the negative impacts of heatwaves on cotton can be buffered by warm growth temperature.

The impacts of global climate change factors on cotton physiology and growth have been documented (Broughton et al., 2020; Broughton et al., 2017; Echer, Oosterhuis, Loka, \& Rosolem, 2014; Loka \& Oosterhuis, 2010; Ullah et al., 2017; Williams et al., 2015), but uncertainty still remains regarding the response of cotton to multiple interactive stress conditions. Here, we investigated the effects of day-time and night-time growth temperature, water deficit and heatwaves on carbon assimilation and growth of cotton. Plants were raised under four temperature treatments under well-watered conditions until the development of flower buds, and then plants from each treatment were subjected to water deficit stress and subsequently to a fiveday heatwave. Leaf gas-exchange characteristics were measured shortly following the heatwave treatment, and during recovery from the heatwave; dry mass production was measured at the end of the experiment. We hypothesised that: (1) warmer daytime growth temperature will increase net carbon assimilation and rates of development, but this beneficial effect is dependent on water availability; (2) nocturnal warming will negatively affect plant biomass production by decreasing net carbon gain; (3) the response to heat and water deficit stress can be modified by growth temperature, therefore warm-grown cotton will be less affected by the heatwave; and (4) cotton is highly resilient to heatwaves, so carbon gain will undergo fast recovery following the mitigation of heat stress.

\section{Plant material and methods}

\section{Plant material and growth conditions}

Cotton seeds (Gossypium hirsutum L. cv. 71BRF [Bollgard II ( Roundup Ready Flex@], CSIRO Australia) were sown in 12 litre black plastic pots filled with water-saturated composted bark and commercial potting mix soil (Australian Native landscapes, Blayney, NSW), and pots were placed into a naturally-lit, temperature-controlled glasshouse located at Western Sydney University, Richmond, NSW, Australia. Emergence occurred approximately 2 weeks after sowing, and plants were then thinned to one individual per pot. In total, 80 individual plants were retained for the experimental treatments. Plants were irrigated daily and fertilised with Aquasol@ (1.6 g/L) $(23.0 \%$ N, $4 \%$ P, $18.0 \%$ K, $0.05 \%$ Zn, $0.06 \%$ Cu, $0.0013 \% \mathrm{Mo}, 0.15 \% \mathrm{Mn}$, $0.06 \% \mathrm{Fe}, 0.011 \% \mathrm{~B}$ ) (Hortico, Victoria, Australia) periodically to ensure growth was not water- or nutrientlimited. During the establishment stage, temperature in the glasshouse was set to $28 / 18{ }^{\circ} \mathrm{C}$ (day/night). Temperature treatment was applied when seedlings reached $c a .5 \mathrm{~cm}$ tall.

\section{Experimental design}

Four adjacent glasshouse bays, each containing 20 randomly selected plants, were used to study the effects of growth temperature, water deficit and heatwave on plant physiology and biomass productivity. Growth temperatures in these compartments were $28 / 18^{\circ} \mathrm{C}, 28 / 22^{\circ} \mathrm{C}, 32 / 22^{\circ} \mathrm{C}$ and $32 / 26^{\circ} \mathrm{C}$ (midday/night), representing two basal temperature regimes (i.e. $28 / 18^{\circ} \mathrm{C}$ and $32 / 22^{\circ} \mathrm{C}$ ) and their corresponding nocturnal warming $\left(+4^{\circ} \mathrm{C}\right)$ scenarios (i.e. $28 / 22{ }^{\circ} \mathrm{C}$ and $32 / 26{ }^{\circ} \mathrm{C}$ ). Temperature was changed five times over $24 \mathrm{~h}$ to simulate the daily temperature cycle in the field. Humidity in the compartments was not controlled. Throughout the experimental period, daily mean relative humidity (RH, \%) across chambers varied between $64.5 \pm 0.1 \%$ and $69.5 \pm 0.1 \%$, with the daily mean atmospheric vapor pressure deficit (VPD, $\mathrm{kPa}$ ) range being $0.98^{\sim} 1.07 \mathrm{kPa} . \mathrm{CO}_{2}$ was maintained at ambient level $(420 \mathrm{ppm})$. Pots were moved and rotated routinely to minimize the environmental heterogeneity within each bay. Soil water content was maintained at field 
capacity until the water deficit stress was applied.

Within each temperature treatment, ten plants were randomly selected for water deficit treatment. Instead of using a priori defined values of soil water content for all plants in the water deficit treatment, water deficit stress was applied as $50 \%$ of the water loss (relative to field capacity) required to induce leaf wilting, to each individual plant. This approach ensured that plants were equally water limited regardless of the temperature treatment given that the water demand of individual plants can vary both within and among temperature treatments (Broughton et al., 2017). For plants assigned to the water deficit treatment, pots were first weighed in the morning on the next day following irrigation. Water was then withheld until leaves were visually wilting. Pots were weighed again, and $50 \%$ of the water lost during the dry-down was added to the pots, and that soil water content was maintained until the end of the experiment. For the well-watered treatment, the soil water content was maintained at field capacity by adding the water loss from the previous day back into the pots. Individual-specific soil water content was maintained by weighing all pots daily in the early morning to determine the total water loss in the previous day, and water loss was supplemented to maintain the soil water content at the desired level during the experiment. Given that elevated growth temperature can accelerate the development of cotton plants (Reddy, Baker, et al., 1991), the water treatment was initiated at 46 days after planting (DAP) for cool temperature regimes (i.e. $28 / 18^{\circ} \mathrm{C}$ and $28 / 22^{\circ} \mathrm{C}$ ) and $38 \mathrm{DAP}$ forwarm temperature regimes (i.e. $32 / 22^{\circ} \mathrm{C}$ and $32 / 26^{\circ} \mathrm{C}$ ) to minimize the confounding effects associated with growth stage.

The heatwave treatment commenced at the beginning of the flowering stage (59 and 79 DAP for warm and cool grown plants, respectively). Five plants within each water $\times$ temperature treatment combination were randomly selected and were transferred into an adjacent bay, within which air temperature was maintained at $40 / 26^{\circ} \mathrm{C}$ (midday/night). Plants were exposed to the heatwave for 5 days, and then pots were moved back to their original growth temperature bays until the end of the experiment. For plants exposed to the heatwave, soil water content was controlled as usual despite potentially higher water consumption.

\section{Leaf gas exchange measurements}

Gas exchange measurements were performed immediately on the day that plants were moved back to their original growth bay (i.e. 63 and 83 DAP for warm and cool grown plants, respectively), as well as on the second and seventh day of recovery following the heatwave treatment. Within each treatment combination, five plants with similar height and leaf number were chosen for leaf gas exchange measurements, which were conducted between 0930 and $1400 \mathrm{~h}$ on one recent, fully expanded leaf per plant with a portable open path gas exchange analyser (LI-6400XT, Li-Cor, Lincoln, NE, USA) equipped with a red-blue diode light source (6400-02B) and an external $\mathrm{CO}_{2}$ injector (6400-01). Light saturated $\mathrm{CO}_{2}$ assimilation rates $\left(\mathrm{A}_{\mathrm{sat}}, \mu \mathrm{mol} \mathrm{m}{ }^{-2}\right.$ $\left.\mathrm{s}^{-1}\right)$, and stomatal conductance $\left(\mathrm{g}_{\mathrm{s}}, \mathrm{mol} \mathrm{m}^{-2} \mathrm{~s}^{-1}\right)$ were measured at $1200 \mu \mathrm{mol} \mathrm{m}{ }^{-2} \mathrm{~s}^{-1}$ photosynthetic photon

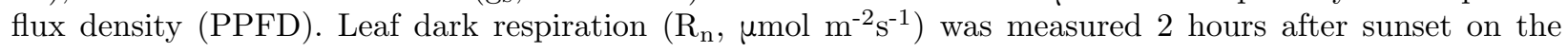
same day with the same leaf used for photosynthesis measurements at zero PPFD. During the gas exchange measurements, $\mathrm{CO}_{2}$ and air temperature in the cuvette were configured to match that of the ambient growth environment, and flow rate was set to $500 \mathrm{~mL} \mathrm{~min}^{-1}$. The range for $\mathrm{RH}$ and VPD in the cuvette was $50^{\sim} 70 \%$ and $1.0^{\sim} 2.0 \mathrm{kPa}$ during the gas exchange measurements, respectively.

\section{Photosynthetic response to temperature}

The responses of net photosynthesis $\left(A_{\text {sat }}\right)$ to temperature were measured about two weeks after commencing the water deficit treatment (i.e. 51 and 58 DAP for warm and cool grown plants, respectively). Five plants within each temperature $\times$ water treatment combination were randomly selected and were transferred to a vacant bay to manipulate the measurement temperature. Measurements were carried out between 0930 and $1400 \mathrm{~h}$ to ensure irradiance was not limiting. Temperature in the glasshouse bay was initially cooled down to $15^{\circ} \mathrm{C}$, and then warmed up to $45^{\circ} \mathrm{C}$ at $5^{\circ} \mathrm{C}$ intervals. Once the desired temperature was achieved, plants were maintained at each targeted temperature for at least $30 \mathrm{~min}$ before measurements were taken to maximize the equilibrium between leaf and air temperature. $\mathrm{A}_{\text {sat }}$ was then recorded at saturated PPFD $\left(1200 \mu \mathrm{mol} \mathrm{m} \mathrm{s}^{-2}\right)$ and growth $\mathrm{CO}_{2}$ concentration $(420 \mathrm{ppm})$, with the temperature in the cuvette tracking 
the ambient air temperature. Photosynthesis temperature (AT) response curves were generated by plotting $\mathrm{A}_{\text {sat }}$ against its corresponding leaf temperature.

\section{Growth and biomass productivity}

Plant growth (as defined by change in plant height) was measured weekly following the emergence of seedlings. The experiment was terminated shortly following the opening of bolls, with the date varying across temperature treatments due to different growth rates. Harvests were performed immediately at the end of the experiment, on $116,123,126$ and $145 \mathrm{DAP}$ for $32 / 26^{\circ} \mathrm{C}, 32 / 22^{\circ} \mathrm{C}, 28 / 22^{\circ} \mathrm{C}$ and $28 / 18^{\circ} \mathrm{C}$ temperature regimes, respectively. The aboveground portion of the plant was collected by excising the stem just above the soil level, and separated into vegetative organs (leaves, stem and branches) and fruits (lint and bract). Plant materials were oven-dried at $70^{\circ} \mathrm{C}$ for at least 72 hours to constant mass before determining dry mass.

\section{Statistical analysis}

The relationship between plant height and DAP was fitted using a three-parameter sigmoidal model, and when DAP for individual height approached $50 \%$ of its maximum height, $\left(\mathrm{H}_{50}\right)$ was calculated and designated as a proxy of growth rate. Leaf AT data were fitted to a quadratic function and the optimum temperature for photosynthesis $\left(\mathrm{T}_{\mathrm{opt}},{ }^{\circ} \mathrm{C}\right.$ ) and $\mathrm{A}_{\text {sat }}$ at $\mathrm{T}_{\mathrm{opt}}$ were estimated (Gunderson, O'hara, Campion, Walker, \& Edwards, 2010). We were limited to four glasshouse bays for our experiment, so we did not have replicate bays for the growth temperature treatments. Therefore, acknowledging pseudo-replication as a function of our complex experimental design, we were limited to considering individual plants within each bay as independent experimental units (i.e. replicate), and subsequently tested the treatment effects with a general linear model, as has been done in our previous studies (Lewis et al. 2013; Duan et al. 2014), as well as in other studies (Apgaua et al. 2019). We used a two-way ANOVA to test the main and interactive effects of temperature and water deficit stress on gas exchange variables, biomass and AT response parameters. We also used a two-way ANOVA to assess the effects of water deficit stress and nocturnal warming within each growth temperature regime (i.e. cool and warm). A three-way ANOVA was used to test the instantaneous effects of growth temperature, water deficit stress and heatwave on leaf gas exchange variables during the heatwave and recovery stage, as well as on harvested biomass at the end of the experiment. The differences in physiological and growth variables across treatment combinations were assessed using Tukey's HSD post hoc . Data were tested for normality and homogeneity of variance before ANOVA was performed. Statistically significant differences were considered if $\mathrm{P}$ [?]0.05. All data and statistical analysis were performed in R 3.5.3 statistical computing environment (R Development Core Team 2014). ANOVA was performed using the $\operatorname{lm}($ ) in combination with the Anova() function in thecar package, and multiple comparisons were conducted with the HSD.test() function in the agricolae package.

\section{Results}

\section{Effects of temperature regime and water deficit on leaf physiology and biomass productivity}

Temperature regime showed significant effects on gas exchange variables including light saturated photosynthetic rate $\left(\mathrm{A}_{\text {sat }} ; \mathrm{P}<0.001\right)$, stomatal conductance $\left(\mathrm{g}_{\mathrm{s}}, \mathrm{P}<0.001\right)$ and the ratio of intercellular to ambient $\mathrm{CO}_{2}\left(\mathrm{C}_{\mathrm{i}} / \mathrm{C}_{\mathrm{a}} ; \mathrm{P}<0.001\right)$ (Figure 1 and 2; Table 1 and $\mathrm{S} 1$ ). Compared with plants grown under cool daytime temperatures, $\mathrm{A}_{\text {sat }}, \mathrm{g}_{\mathrm{s}}$ and $\mathrm{C}_{\mathrm{i}} / \mathrm{C}_{\mathrm{a}}$ increased by $31.5 \%, 105.6 \%$ and $10.5 \%$, respectively, under warm day growth temperatures. In addition, rates of leaf dark respiration $\left(R_{n}\right)$ were significantly increased by growth temperature $(\mathrm{P}<0.001)$, with $\mathrm{R}_{\mathrm{n}}$ being $30.3 \%$ higher in warm grown plants than in cool grown plants, although this pattern was less clear in the well-watered treatment (Figure 1, Table S1). On the other hand, water deficit treatment did not alter most gas exchange variables, except for $R_{n}$, which was decreased by $11 \%$ in response to water deficit stress, on average. A significant interaction was detected for temperature and water treatment on leaf level carbon balance represented by the difference between $\mathrm{A}_{\text {sat }}$ and $R_{n}\left(A_{\text {sat }}-R_{n} ; P<0.001\right)$. However, the variation of leaf carbon balance across treatments was primarily driven by growth temperature rather than water availability, given that $\mathrm{A}_{\mathrm{sat}}-\mathrm{R}_{\mathrm{n}}$ increased by $10.7 \%$ in warm grown plants compared with cool grown plants, but decreased by $2 \%$ in the well-watered treatment relative to water deficit treatment, on average. 
Warmer growth temperature had significant effects on the optimum temperature of photosynthesis $\left(\mathrm{T}_{\mathrm{opt}}\right.$; $\mathrm{P}=0.02$ ) (Figure 3, Table 2). $\mathrm{T}_{\mathrm{opt}}$ of plants grown under $28 / 22^{\circ} \mathrm{C}$ was higher than $\mathrm{T}_{\mathrm{opt}}$ of the other temperature treatments $\left(c a .+1^{\circ} \mathrm{C}\right)$; nonetheless, the variation in $\mathrm{T}_{\mathrm{opt}}$ across temperature treatments was relatively minor. There was a significant interaction between growth temperature and water treatment on photosynthetic rate at $\mathrm{T}_{\mathrm{opt}}\left(\mathrm{A}_{\mathrm{opt}} ; \mathrm{P}=0.03\right)$. Growth temperature was the main determinant of the variation across treatments given that the difference induced by the water treatment was small for all temperature treatments.

Both temperature regime and water treatment showed significant main effects on the number of days required for plant height to reach $50 \%$ of its maximum height $\left(\mathrm{H}_{50} ; \mathrm{P}<0.01\right.$ for both treatments); $\mathrm{H}_{50}$ was higher at cool temperatures and in the well-watered treatment on average (Figure 4; Table 1 and S2). Growth temperature and water regime showed significant interactive effects on the dry mass of vegetative organs $(\mathrm{P}$ $<0.01)$, as well as total aboveground dry mass $(\mathrm{P}<0.05)$. Although the pattern of variation across treatment combinations was less evident, both variables were generally decreased by elevated growth temperature and water deficit stress. In addition, growth temperature and water independently affected the fruit biomass $(\mathrm{P}$ $<0.001$ for both treatments), with values lower under the warm temperature regimes $(-15.6 \%)$ and water deficit treatment $(-11.8 \%)$ compared with cool temperature regimes and well-watered treatment, respectively (Table S2).

\section{Effects of nocturnal warming and water deficit on leaf carbon gain and biomass productivity}

There were no interactive effects of nocturnal warming and water treatment on $\mathrm{A}_{\text {sat }}$ in both temperature regimes (i.e. cool and warm; Table 3); while significant main effects were observed for nocturnal warming under cool temperature regime $(\mathrm{P}<0.01)$ and for water treatment under warm temperature regime $(\mathrm{P}=0.02)$, but these effects were generally small (Figure 1). Although both treatments had no significant effects on $R_{n}$, the variation of $A_{\text {sat }}-R_{n}$ within each temperature regime was similar to that of $A_{\text {sat }}$, with the main effect found for temperature $(\mathrm{P}<0.01)$ and water treatment $(\mathrm{P}<0.01)$ under cool and warm temperature regimes, respectively (Figure 2).

Within the cool temperature regime, nocturnal warming did not affect vegetative $(\mathrm{P}=0.17)$, fruit $(\mathrm{P}=0.36)$ or total biomass $(\mathrm{P}=0.69)$, while all biomass variables were significantly reduced under water-limited conditions compared with well-watered conditions ( $\mathrm{P}<0.05$ for all variables; Figure 6 , Table 3 ). Within the warm temperature regime, significant interactive effects between nocturnal warming and water treatment were observed for biomass production $(\mathrm{P}<0.001$ for all variables). Dry mass production was promoted by warm night temperatures under well-watered conditions, but was reduced or unchanged under water deficit stress.

\section{Effects of growth temperature, drought and heatwave on carbon gain and biomass productivity}

Strong interactive effects were observed among growth temperature and heatwave treatments for gas exchange parameters, including $\mathrm{A}_{\mathrm{sat}}, \mathrm{g}_{\mathrm{s}}, \mathrm{R}_{\mathrm{n}}$ and $\mathrm{C}_{\mathrm{i}} / \mathrm{C}_{\mathrm{a}}$ (Figure 1 , Table 4 and $\mathrm{S} 1$ ). For all variables, the values were increased by the heatwave under cool growth temperatures, with an opposite pattern observed for plants grown under warm temperatures. In addition, temperature, water deficit and heatwave conditions interactively affected the leaf carbon balance (Figure 2, Table 4). The values of $A_{\text {sat }}-R_{n}$ displayed a similar pattern to that of other gas exchange variables across growth temperature and heatwave treatments, yet the difference associated with water deficit stress was small. The differences in gas exchange variables during the heatwave remained detectable on the second day of recovery (Figure 5, Table 4), with significant interactions between growth temperature and heatwave on $A_{s a t}$ and $A_{s a t}-R_{n}(P<0.001$ for both variables $)$, but not $g_{s}$ $(\mathrm{P}=0.43)$. However, the differences caused by the heatwave within each growth temperature and water treatment was greatly diminished. Furthermore, the difference in gas exchange variables related to the heatwave disappeared in some growth temperature $\times$ water treatment combinations on the seventh day of recovery (data not shown).

Temperature and heatwave interactively affected vegetative dry mass. Heatwave increased vegetative mass production in three of the four growth temperature treatments, with the exception of $28 / 22^{\circ} \mathrm{C}$, in which 
vegetative growth was not altered by the heatwave (Figure 6, Table 4 and S2). Fruit mass was decreased in response to the heatwave across all growth temperatures, with the negative effects more prominent for warm temperature regimes $(-14.8 \%)$ compared with cool temperature regimes $(-7.1 \%)$, as well as across water treatments $(-10.4 \%$ and $-11.1 \%$ for well-watered and water deficit treatment, respectively), but the total aboveground biomass was not changed by the heatwave (Table S2).

\section{Discussion}

In partial support of our first hypothesis, warmer daytime temperatures did lead to increased leaf level carbon gain, but not biomass production. Water deficit stress slightly reduced carbon gain and biomass production independent of temperature. Our second hypothesis was largely rejected given that both photosynthesis and respiration, and in turn leaf level carbon balance, were not strongly altered by nocturnal warming. Additionally, the impact of nocturnal warming on biomass production was only found for plants under elevated daytime temperature, with the direction of effect depending on water regime. Contrary to the third hypothesis that warm-grown plants would be less affected by the heatwave, leaves of plants in warmer temperature regimes showed decreased carbon gain during short-term heat stress despite the occurrence of thermal acclimation in photosynthesis. On the other hand, leaf carbon gain was promoted by the heatwave in cool-grown plants. Although a legacy effect of heatwave on carbon gain was observed on the second day of recovery, differences in gas exchange variables triggered by heat stress were generally small and disappeared in some cases on the seventh day of recovery, thereby supporting our fourth hypothesis. Consequently, the heatwave generated minor effects on total biomass production, but cotton final reproductive biomass was reduced. Taken together, these results demonstrate the complexity regarding the potential impacts of climate change on cotton plants, and highlight the important role of growth temperature in regulating cotton carbon assimilation and growth.

\section{Soil water deficit and warming independently affect leaf carbon gain and biomass production}

We show that elevated growth temperature increased carbon assimilation. This is consistent with the observation of Osanai et al. (2017) on cotton plants with similar temperature treatments, and is also in accordance with studies showing up-regulated carbon assimilation rate under warmer growth temperature within the optimum thermal range (Downton \& Slatyer, 1972; Reddy, Baker, et al., 1991; Reddy, Reddy, \& Hodges, 1995). Early studies revealed that cotton growth was thermally sensitive, with carbon assimilation and dry mass production greatly decreased when growing under unfavourable temperature regimes (Reddy, Baker, et al., 1991). Downton and Slatyer (1972) reported that the carbon assimilation of cotton was maximized at $25 / 20^{\circ} \mathrm{C}$. However, modern varieties are commonly more heat tolerant, such that stability of photosynthesis can be retained at higher temperatures up to $36^{\circ} \mathrm{C}$ (Zhao, Reddy, Kakani, Koti, \& Gao, 2005). The upregulation in $\mathrm{A}_{\text {sat }}$ at higher growth temperatures indicates that the elevated temperature treatment was still within the thermal optimum range of this cotton variety. Increased $A_{\text {sat }}$ can be partially attributed to higher $\mathrm{g}_{\mathrm{s}}$ under warmer growth temperatures, which alleviated some of the stomatal limitation on photosynthesis, as evidenced by increased $C_{i} / C_{a}$ under these temperatures. An increase in $A_{\text {sat }}$ under warmer growth temperatures may also be facilitated by thermal acclimation of photosynthesis, as signified by the higher $\mathrm{A}_{\mathrm{opt}}$ at warmer temperature regimes. This occurred despite the relatively unchanged $\mathrm{T}_{\mathrm{opt}}$ across temperature treatments (Way \& Yamori, 2014), and might be underpinned by adjustments in biochemical components of photosynthesis such as Rubisco carboxylation and electron transport, as well as antioxidative capacity (Kurek et al., 2007; Law et al., 2001; Law \& Crafts-Brandner, 1999). On the other hand, decreased soil water availability had relatively minor effects on $\mathrm{A}_{\text {sat }}$, probably because the water deficit stress was moderate and did not generate substantial physiological effects; e.g. the lowest $\mathrm{g}_{\mathrm{s}}$ in the water deficit treatment $\left(0.38 \mathrm{~mol} \mathrm{~m}^{-2} \mathrm{~s}^{-1}\right)$ was only slightly lower than the $\mathrm{g}_{\mathrm{s}}$ threshold defining the initiation of drought-induced down-regulation of photosynthesis (i.e. $0.4 \mathrm{~mol} \mathrm{~m}^{-2} \mathrm{~s}^{-1}$ ) (Medrano, Escalona, Bota, Gulías, \& Flexas, 2002).

The decreased $\mathrm{H}_{50}$ for plants in warm temperature regimes demonstrated the stimulatory effect of high temperature on developmental rate, which is consistent with many previous studies (Gipson, 1986; Reddy, Reddy, \& Hodges, 1992; Reddy, Davidonis, Johnson, \& Vinyard, 1999). However, aboveground dry mass was reduced by elevated growth temperatures despite increased leaf level carbon assimilation. The higher 
vegetative dry mass under cool temperature regimes was similar to Reddy et al. (1992), who suggested that vegetative growth was favored by lower temperatures. Meanwhile, plants grown under cool temperature regimes also exhibited higher fruit dry mass. Similarly, Pettigrew (2008) reported that lint yield was slightly decreased in response to $+1^{\circ} \mathrm{C}$ warming for field grown cotton. Together, these results suggest that warm growth temperature will compromise cotton growth and yield despite the positive effect on leaf carbon assimilation.

\section{Impacts of nocturnal warming on plant performance depends on temperature regime}

Studies examining the effects of nocturnal warming on plants are ambiguous, with some species exhibiting lower photosynthesis and yield, but an opposite pattern being observed for other species (Echer et al., 2014; Frantz, Cometti, \& Bugbee, 2004; Mohammed \& Tarpley, 2009; Prasad et al., 2008; Xu, Zhou, \& Shimizu, 2009). The underlying mechanisms linking nocturnal warming and rates of photosynthesis are uncertain, but may relate to the source-sink strength for carbohydrates, which has been shown to exert control on photosynthesis in a feedback manner (Paul \& Pellny, 2003). In cotton plants, it is proposed that night-time warming may inhibit photosynthesis (Reddy, Reddy, et al., 1991). However, our results showed that leaf $\mathrm{A}_{\text {sat }}$ was not strongly affected by $+4^{\circ} \mathrm{C}$ night-time temperature regardless of the day-time temperature regime. In addition, $R_{n}$ was unaffected by elevated night-time temperature, which is consistent with Frantz et al. (2004) and Soliz et al. (2008), probably due to a low thermal sensitivity of respiration. This may explain the unchanged $\mathrm{A}_{\text {sat }}$ by nocturnal warming, given that the constraint on photosynthesis imposed by carbohydrate sink strength was not ameliorated by respiration, as has also been demonstrated in trees (Turnbull, Murthy, \& Griffin, 2002; Turnbull et al., 2004).

We expected that night-time warming would increase respiration and decrease net carbon gain and biomass production in cotton, unless photosynthesis was elevated by warming. However, biomass was unaffected or increased by nocturnal warming in some cases, suggesting that the response to nocturnal warming may be species-specific ( $\mathrm{Li}$ et al., 2014; Wolfe-Bellin et al., 2006). Although leaf carbon balance was not strongly affected by nocturnal warming in the present study, aboveground biomass production was dependent on both temperature and water treatments. Of note, Echer et al. (2014) reported that increasing nocturnal growth temperature $\left(+5{ }^{\circ} \mathrm{C}\right)$ from $32 / 24^{\circ} \mathrm{C}$ to $32 / 29^{\circ} \mathrm{C}$ decreased reproductive dry mass. In our study, fruit mass production was stable up to $32 / 26^{\circ} \mathrm{C}$ in the warmer nocturnal temperature regime, indicating that cotton yield response to elevated night-time temperature may be a threshold-like function (Schlenker \& Roberts, 2009).

\section{Heat stress alters carbon gain but not biomass production}

Heat stress impairs carbon assimilation mainly by lowering Rubisco activity, which corresponds to the declining activation state of Rubisco due to the thermal lability of Rubisco activase (Sharwood, 2017). In addition, experimental evidence suggests that increasing thylakoid membrane permeability, thus reducing the amount of ATP and reductant due to electron leakage (Chavan et al., 2019; Law et al., 2001; Law \& Crafts-Brandner, 1999). Plants pre-conditioned at warmer temperatures can display advanced thermal stability, so that photosynthesis is less affected during heat stress (Kurek et al., 2007; Law et al., 2001). In the present study, the significant interactions between temperature regime and heatwave provide evidence that the potential impacts of heat stress can be modified by the thermal history of cotton. We found that $\mathrm{A}_{\text {sat }}$ increased for plants grown under cool temperatures but decreased at warm temperatures when exposed to the heatwave, suggesting that thermal acclimation did not positively affect carbon assimilation during the heatwave. Indeed, the response of $\mathrm{A}_{\text {sat }}$ to the heatwave cannot be explained by thermal acclimation to growth temperature given that warm-grown plants exhibited higher $\mathrm{A}_{\text {sat }}$ than cool-grown plants up to $45^{\circ} \mathrm{C}$ according to the AT response curves. Alternatively, the response pattern of $\mathrm{A}_{\text {sat }}$ may be partially associated with the variation in $\mathrm{g}_{\mathrm{s}}$. Increased $\mathrm{g}_{\mathrm{s}}$ during short-term heat stress has been observed (Najeeb et al., 2017), which apparently mitigates the stomatal limitation on photosynthesis, and also protects the integrity of the photosynthetic machinery by increasing RuBP regeneration capacity, thus facilitating carbon assimilation (Chavan et al., 2019). Noticeably, the response of $g_{s}$ to the heatwave was temperature regime dependent, which was similar to Hamilton III et al. (2008), who observed decreased g following a heatwave in warm- 
grown, but not cool-grown Chenopodium album, indicating a nonlinear relationship between the response of $g_{s}$ to heatwaves and growth temperature.

Rates of $R_{n}$ exhibited marked increase in response to the heatwave treatment, suggesting a limited thermal acclimation capacity (Atkin \& Tjoelker, 2003). This, together with reduced $\mathrm{A}_{\text {sat }}$, resulted in decreased leaf carbon gain for leaves exposed to heat stress under warm temperature regimes, while the negative effects of increased $R_{n}$ on carbon balance was compensated by increased $A_{\text {sat }}$ under cool temperature regimes. However, gas exchange variables exhibited fast recovery following the mitigation of heat stress, indicating that the carbon gain of cotton plants was highly resilient to heatwaves and may not affect aboveground biomass production, which did not differ between control and heat stressed plants. However, the heatwave led to the reduction in fruit mass, with the extent of the decrease dependent on growth temperature, illustrating the negative effects of heat stress on cotton yield.

\section{Conclusions}

The current study examined the effects of growth temperature, water deficit and heatwave on leaf carbon gain and biomass production in cotton plants. Warmer growth temperature promoted growth rate and leaf level carbon gain due to greater stomatal conductance and thermal acclimation of photosynthesis, but compromised aboveground dry mass production. Furthermore, growth temperature affected the response of leaf carbon gain and/or yield to nocturnal warming and heat stress. Water stress also exerted control over carbon gain and reproductive dry matter, either independently or interactively, but these effects were less pronounced. The instantaneous impacts of the heatwave on carbon gain and biomass production was largely neutralized, yet fruit biomass was negatively affected.

Overall, temperature appears to be a major determinant of biomass production in cotton. More specifically, both short- and long-term increases in daytime temperature will lead to reduced cotton yields, while nocturnal warming has limited capacity to alter that impact. Additionally, yield will not be strongly diminished if soil water content is maintained well above the level triggering leaf wilting. Therefore, plant traits enabling heat tolerance especially for heatwave conditions should continually be targeted and prioritized in future breeding selection. This study adds to the current knowledge about the impacts of global climate change on cotton by providing evidence of the response of carbon gain and biomass to some of the key climate change factors, and highlights the interactive effects of environmental factors on plant growth. Subsequent studies in the field are required to more fully uncover the mechanisms that can be used to model crop yield under future climates.

Conflict of interest: The authors declare that they have no conflict of interest.

\section{References}

Apgaua, D. M., Tng, D. Y., Forbes, S. J., Ishida, Y. F., Vogado, N. O., Cernusak, L. A., \& Laurance, S. G. (2019). Elevated temperature and $\mathrm{CO}_{2}$ cause differential growth stimulation and drought survival responses in eucalypt species from contrasting habitats. Tree physiology , 39 (11), 1806-1820.

Atkin, O. K., \& Tjoelker, M. G. (2003). Thermal acclimation and the dynamic response of plant respiration to temperature. Trends in plant science, 8 (7), 343-351.

Bange, M. (2007). Effects of climate change on cotton growth and development. The Australian Cottongrower, 28 (3), 41-45.

Bange, M., Carberry, P., Marshall, J., \& Milroy, S. (2005). Row configuration as a tool for managing rainfed cotton systems: review and simulation analysis. Australian Journal of Experimental Agriculture, 45 (1), $65-77$.

Broughton, K., Bange, M., Tissue, D. T., Osanai, Y., Nguyen, L., Luo, Q., . . Payton, P. (2020). An overview of recent research into effects of climate change \& extreme weather events on Australian cotton systems. www.cottoninfo.com.au . 
Broughton, K. J., Smith, R. A., Duursma, R. A., Tan, D. K., Payton, P., Bange, M. P., \& Tissue, D. T. (2017). Warming alters the positive impact of elevated $\mathrm{CO}_{2}$ concentration on cotton growth and physiology during soil water deficit. Functional Plant Biology, 44 (2), 267-278.

Burke, J. J., \& Wanjura, D. F. (2010). Plant responses to temperature extremes. In J. McD. Stewart, D. M. Oosterhuis, J. J. Heitholt \& J. R. Mauney (Eds), Physiology of Cotton (pp. 123-128). Berlin: Springer.

Carmo-Silva, A. E., Gore, M. A., Andrade-Sanchez, P., French, A. N., Hunsaker, D. J., \& Salvucci, M. E. (2012). Decreased $\mathrm{CO}_{2}$ availability and inactivation of Rubisco limit photosynthesis in cotton plants under heat and drought stress in the field. Environmental and Experimental Botany, 83 , 1-11.

Chastain, D. R., Snider, J. L., Collins, G. D., Perry, C. D., Whitaker, J., \& Byrd, S. A. (2014). Water deficit in field-grown Gossypium hirsutum primarily limits net photosynthesis by decreasing stomatal conductance, increasing photorespiration, and increasing the ratio of dark respiration to gross photosynthesis. Journal of Plant Physiology, 171 (17), 1576-1585.

Chavan, S. G., Duursma, R. A., Tausz, M., \& Ghannoum, O. (2019). Elevated $\mathrm{CO}_{2}$ alleviates the negative impact of heat stress on wheat physiology but not on grain yield. Journal of experimental botany, 70 (21), 6447-6459.

Dai, A. (2013). Increasing drought under global warming in observations and models. Nature climate change, $3(1), 52-58$

Downton, J., \& Slatyer, R. (1972). Temperature dependence of photosynthesis in cotton. Plant physiology, 50 (4), 518-522.

Duan, H., Duursma, R. A., Huang, G., Smith, R. A., Choat, B., O’GRADY, A. P., \& Tissue, D. T. (2014). Elevated $\left[\mathrm{CO}_{2}\right]$ does not ameliorate the negative effects of elevated temperature on drought-induced mortality in E ucalyptus radiata seedlings. Plant, Cell \&3 Environment, 37 (7), 1598-1613.

Echer, F., Oosterhuis, D., Loka, D., \& Rosolem, C. (2014). High night temperatures during the floral bud stage increase the abscission of reproductive structures in cotton. Journal of agronomy and crop science, 200 (3), 191-198.

Flexas, J., Bota, J., Loreto, F., Cornic, G., \& Sharkey, T. (2004). Diffusive and metabolic limitations to photosynthesis under drought and salinity in C3 plants. Plant biology, 6 (03), 269-279.

Frantz, J. M., Cometti, N. N., \& Bugbee, B. (2004). Night temperature has a minimal effect on respiration and growth in rapidly growing plants. Annals of Botany, 94 (1), 155-166.

Gipson, J., \& Joham, H. (1968). Influence of Night Temperature on Growth and Development of Cotton (Gossypium hirsutum L.). I. Fruiting and Boll Development 1. Agronomy Journal, 60 (3), 292-295.

Gipson, J. R. (1986). Temperature effects on growth, development, and fiber properties. In J.R. Mauney \& J. McD Stewart (Eds), Cotton physiology (pp. 47-56). Memphis: Cotton Foundation.

Gunderson, C. A., O'hara, K. H., Campion, C. M., Walker, A. V., \& Edwards, N. T. (2010). Thermal plasticity of photosynthesis: the role of acclimation in forest responses to a warming climate. Global Change Biology, 16 (8), 2272-2286.

Haldimann, P., \& Feller, U. (2005). Growth at moderately elevated temperature alters the physiological response of the photosynthetic apparatus to heat stress in pea (Pisum sativum L.) leaves.Plant, Cell $\mathscr{E}$ Environment, 28 (3), 302-317.

Hamilton III, E. W., Heckathorn, S. A., Joshi, P., Wang, D., \& Barua, D. (2008). Interactive effects of elevated $\mathrm{CO}_{2}$ and growth temperature on the tolerance of photosynthesis to acute heat stress in $\mathrm{C} 3$ and $\mathrm{C} 4$ species. Journal of Integrative Plant Biology, 50 (11), 1375-1387. 
Impa, S., Nadaradjan, S., \& Jagadish, S. (2012). Drought stress induced reactive oxygen species and antioxidants in plants. In P. Ahmad \& M.N.V. Prasad (Eds). Abiotic Stress Responses in Plants (pp. 131-147). Berlin: Springer.

Izquierdo, N., Aguirrezabal, L., Andrade, F., \& Pereyra, V. (2002). Night temperature affects fatty acid composition in sunflower oil depending on the hybrid and the phenological stage. Field Crops Research, 77 (2-3), 115-126.

Kitao, M., \& Lei, T. (2007). Circumvention of over-excitation of PSII by maintaining electron transport rate in leaves of four cotton genotypes developed under long-term drought. Plant biology, 9 (01), 69-76.

Kurek, I., Chang, T. K., Bertain, S. M., Madrigal, A., Liu, L., Lassner, M. W., \& Zhu, G. (2007). Enhanced thermostability of Arabidopsis Rubisco activase improves photosynthesis and growth rates under moderate heat stress. The Plant Cell, 19 (10), 3230-3241.

Larkindale, J., \& Vierling, E. (2008). Core genome responses involved in acclimation to high temperature. Plant physiology, 146 (2), 748-761.

Law, D. R., Crafts-Brandner, S. J., \& Salvucci, M. E. (2001). Heat stress induces the synthesis of a new form of ribulose-1, 5-bisphosphate carboxylase/oxygenase activase in cotton leaves. Planta, 214 (1), 117-125.

Law, R. D., \& Crafts-Brandner, S. J. (1999). Inhibition and acclimation of photosynthesis to heat stress is closely correlated with activation of ribulose-1, 5-bisphosphate carboxylase/oxygenase. Plant physiology, 120 (1), 173-182.

Lewis, J. D., Smith, R. A., Ghannoum, O., Logan, B. A., Phillips, N. G., \& Tissue, D. T. (2013). Industrialage changes in atmospheric $\left[\mathrm{CO}_{2}\right]$ and temperature differentially alter responses of faster-and slower-growing Eucalyptus seedlings to short-term drought. Tree Physiology , 33 (5), 475-488.

Li, X., Smith, R., Choat, B., \& Tissue, D. T. (2019). Drought resistance of cotton (Gossypium hirsutum ) is promoted by early stomatal closure and leaf shedding. Functional Plant Biology , 47 (2), 91-98.

Li, Z., Lin, J., Zhang, T., Zhang, N., Mu, C., \& Wang, J. (2014). Effects of summer nocturnal warming on biomass production ofLeymus chinensis in the Songnen grassland of $\mathrm{C}$ hina: from bud bank and photosynthetic compensation. Journal of agronomy and crop science, 200 (1), 66-76.

Loka, D., \& Oosterhuis, D. (2010). Effect of high night temperatures on cotton respiration, ATP levels and carbohydrate content.Environmental and Experimental Botany, 68 (3), 258-263.

Long S.P. \& Ort D.R. (2010). More than taking the heat: crops and global change. Current Opinion in Plant Biology, 13 (3), 241-248.

Medrano, H., Escalona, J. M., Bota, J., Gulias, J., \& Flexas, J. (2002). Regulation of photosynthesis of C3 plants in response to progressive drought: stomatal conductance as a reference parameter.Annals of Botany, 89 (7), 895-905.

Mohammed, A., \& Tarpley, L. (2009). High nighttime temperatures affect rice productivity through altered pollen germination and spikelet fertility. Agricultural and Forest Meteorology, 149 (6-7), 999-1008.

Najeeb, U., Sarwar, M., Atwell, B. J., Bange, M. P., \& Tan, D. K. (2017). Endogenous ethylene concentration is not a major determinant of fruit abscission in heat-stressed cotton (Gossypium hirsutum L.).Frontiers in plant science, 8 , 1615. doi: 10.3389/fpls.2017.01615

Osanai, Y., Tissue, D. T., Bange, M. P., Anderson, I. C., Braunack, M. V., \& Singh, B. K. (2017). Plantsoil interactions and nutrient availability determine the impact of elevated $\mathrm{CO}_{2}$ and temperature on cotton productivity. Plant and Soil, 410 (1-2), 87-102.

Pachauri, R. K., Allen, M. R., Barros, V. R., Broome, J., Cramer, W., Christ, R., . . . Dasgupta, P. (2014). Climate change 2014: synthesis report. Contribution of Working Groups I, II and III to the fifth assessment 
report of the Intergovernmental Panel on Climate Change. IPCC.

Paul, M. J., \& Pellny, T. K. (2003). Carbon metabolite feedback regulation of leaf photosynthesis and development. Journal of experimental botany, 54 (382), 539-547.

Perkins, S., Alexander, L., \& Nairn, J. (2012). Increasing frequency, intensity and duration of observed global heatwaves and warm spells. Geophysical Research Letters, 39 (20). doi.org/10.1029/2012GL053361

Pettigrew, W. (2001). Environmental effects on cotton fiber carbohydrate concentration and quality. Crop science, 41 (4), 1108-1113.

Pettigrew, W. (2008). The effect of higher temperatures on cotton lint yield production and fiber quality. Crop science, 48 (1), 278-285.

Prasad, P., Pisipati, S., Ristic, Z., Bukovnik, U., \& Fritz, A. (2008). Impact of nighttime temperature on physiology and growth of spring wheat. Crop science, 48 (6), 2372-2380.

Prasad, P. V., \& Djanaguiraman, M. (2011). High night temperature decreases leaf photosynthesis and pollen function in grain sorghum.Functional Plant Biology, 38 (12), 993-1003.

Reddy, K., Hodges, H., \& Reddy, V. (1992). Temperature effects on cotton fruit retention. Agronomy Journal, 84 (1), 26-30.

Reddy, K., Reddy, V., \& Hodges, H. (1992). Temperature effects on early season cotton growth and development. Agronomy Journal, 84 (2), 229-237.

Reddy, K. R., Davidonis, G. H., Johnson, A. S., \& Vinyard, B. T. (1999). Temperature regime and carbon dioxide enrichment alter cotton boll development and fiber properties. Agronomy Journal, 91 (5), 851-858.

Reddy, K. R., Hodges, H. F., \& McKinion, J. M. (1997). A comparison of scenarios for the effect of global climate change on cotton growth and yield. Functional Plant Biology, 24 (6), 707-713.

Reddy, V., Baker, D., \& Hodges, H. (1991). Temperature effects on cotton canopy growth, photosynthesis, and respiration. Agronomy Journal, 83 (4), 699-704.

Reddy, V., Reddy, K., \& Baker, D. (1991). Temperature effect on growth and development of cotton during the fruiting period. Agronomy Journal, 83 (1), 211-217.

Reddy, V., Reddy, K., \& Hodges, H. (1995). Carbon dioxide enrichment and temperature effects on cotton canopy photosynthesis, transpiration, and water-use efficiency. Field Crops Research, 41 (1), 13-23.

Salvucci, M. E., \& Crafts-Brandner, S. J. (2004). Relationship between the heat tolerance of photosynthesis and the thermal stability of Rubisco activase in plants from contrasting thermal environments. Plant physiology, 134 (4), 1460-1470.

Schlenker, W., \& Roberts, M. J. (2009). Nonlinear temperature effects indicate severe damages to US crop yields under climate change.Proceedings of the National Academy of sciences, 106 (37), 15594-15598.

Sekmen, A. H., Ozgur, R., Uzilday, B., \& Turkan, I. (2014). Reactive oxygen species scavenging capacities of cotton (Gossypium hirsutum ) cultivars under combined drought and heat induced oxidative stress. Environmental and Experimental Botany, 99 , 141-149.

Sharwood, R. E. (2017). Engineering chloroplasts to improve Rubisco catalysis: prospects for translating improvements into food and fiber crops. New Phytologist, 213 (2), 494-510.

Singh, R. P., Prasad, P. V., Sunita, K., Giri, S., \& Reddy, K. R. (2007). Influence of high temperature and breeding for heat tolerance in cotton: a review. Advances in Agronomy, 93 , 313-385.

Sinsawat, V., Leipner, J., Stamp, P., \& Fracheboud, Y. (2004). Effect of heat stress on the photosynthetic apparatus in maize (Zea maysL.) grown at control or high temperature. Environmental and Experimental Botany, 52 (2), 123-129. 
Snider, J. L., Chastain, D. R., Meeks, C. D., Collins, G. D., Sorensen, R. B., Byrd, S. A., \& Perry, C. D. (2015). Predawn respiration rates during flowering are highly predictive of yield response in Gossypium hirsutum when yield variability is water-induced.Journal of Plant Physiology, 183 , 114-120.

Snider, J. L., Oosterhuis, D. M., Skulman, B. W., \& Kawakami, E. M. (2009). Heat stress-induced limitations to reproductive success in Gossypium hirsutum . Physiologia plantarum, 137 (2), 125-138.

Soliz, L. M. A., Oosterhuis, D. M., Coker, D. L., \& Brown, R. S. (2008). Physiological response of cotton to high night temperature.Am. J. Plant Sci. Biotechnol, 2, 63-68.

Turnbull, M., Murthy, R., \& Griffin, K. (2002). The relative impacts of daytime and night-time warming on photosynthetic capacity in Populus deltoides. Plant, Cell 83 Environment, 25 (12), 1729-1737.

Turnbull, M. H., Tissue, D. T., Murthy, R., Wang, X., Sparrow, A. D., \& Griffin, K. L. (2004). Nocturnal warming increases photosynthesis at elevated $\mathrm{CO}_{2}$ partial pressure in Populus deltoides . New Phytologist, $161(3), 819-826$.

Ullah, A., Sun, H., Yang, X., \& Zhang, X. (2017). Drought coping strategies in cotton: increased crop per drop. Plant biotechnology journal, 15 (3), 271-284.

Wang, R., Ji, S., Zhang, P., Meng, Y., Wang, Y., Chen, B., \& Zhou, Z. (2016). Drought effects on cotton yield and fiber quality on different fruiting branches. Crop science, 56 (3), 1265-1276.

Way, D. A., \& Yamori, W. (2014). Thermal acclimation of photosynthesis: on the importance of adjusting our definitions and accounting for thermal acclimation of respiration. Photosynthesis research, 119 (1-2), 89-100.

Williams, A., White, N., Mushtaq, S., Cockfield, G., Power, B., \& Kouadio, L. (2015). Quantifying the response of cotton production in eastern Australia to climate change. Climatic change, 129 (1-2), 183-196.

Wolfe-Bellin, K. S., He, J., \& Bazzaz, F. (2006). Leaf-level physiology, biomass, and reproduction of Phytolacca americana under conditions of elevated carbon dioxide and increased nocturnal temperature. International journal of plant sciences, 167 (5), 1011-1020.

Xu, Z., Zhou, G., \& Shimizu, H. (2009). Effects of soil drought with nocturnal warming on leaf stomatal traits and mesophyll cell ultrastructure of a perennial grass. Crop science, 49 (5), 1843-1851.

Yamori, W., Hikosaka, K., \& Way, D. A. (2014). Temperature response of photosynthesis in C3, C4, and CAM plants: temperature acclimation and temperature adaptation. Photosynthesis research, 119 (1-2), 101-117.

Yi, X., Zhang, Y., Yao, H., Luo, H., Gou, L., Chow, W., \& Zhang, W. (2016). Different strategies of acclimation of photosynthesis, electron transport and antioxidative activity in leaves of two cotton species to water deficit. Functional Plant Biology, 43 (5), 448-460.

Zhao, D., Reddy, K. R., Kakani, V. G., Koti, S., \& Gao, W. (2005). Physiological causes of cotton fruit abscission under conditions of high temperature and enhanced ultraviolet-B radiation. Physiologia plantarum, 124 (2), 189-199.

Zhu, L., Bloomfield, K. J., Hocart, C. H., Egerton, J. J., O’Sullivan, O. S., Penillard, A., . . . Atkin, O. K. (2018). Plasticity of photosynthetic heat tolerance in plants adapted to thermally contrasting biomes. Plant, Cell \& Environment, 41 (6), 1251-1262.

\section{Figures \& Tables}

Figure 1 Impacts of growth temperature, water regime and heatwave on leaf photosynthetic rate $\left(\mathrm{A}_{\text {sat }}\right.$; panel a, b), stomatal conductance ( $g_{s}$; panel c, d) and dark respiration rate $\left(R_{n}\right.$; panel e, f) of cotton plants. Bars indicate mean value for each treatment combination and error bars represent standard error of mean 
$(\mathrm{n}=5)$. Thermal regimes characterized by different daytime temperature (i.e. $32 / 22^{\circ} \mathrm{C}$ and $32 / 26^{\circ} \mathrm{C}$ ) are indicated by hatched bars.

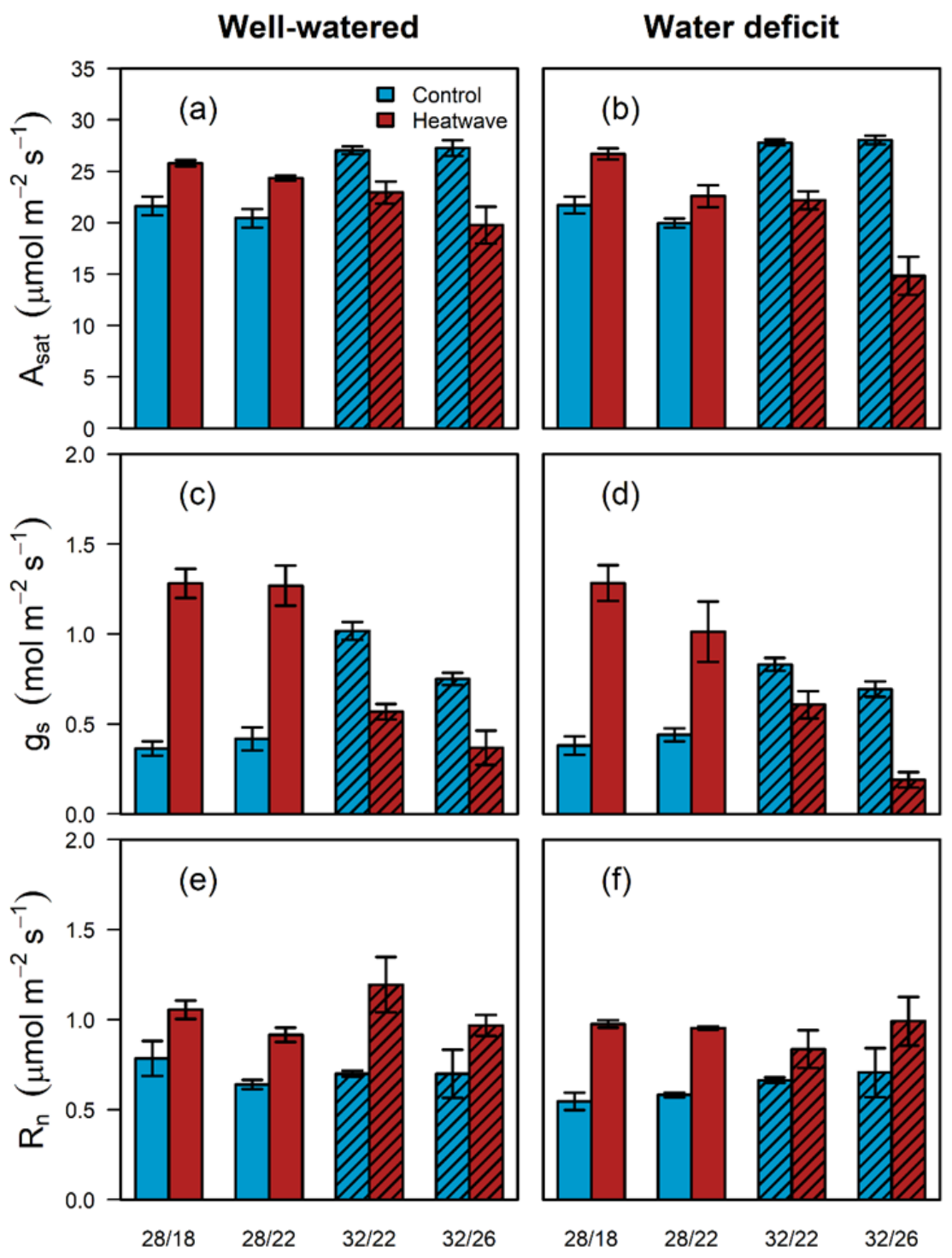

Figure 2 Impacts of growth temperature, water regime and heatwave on the ratio of intercellular to atmospheric $\mathrm{CO}_{2}\left(\mathrm{C}_{\mathrm{i}} / \mathrm{C}_{\mathrm{a}}\right.$; panel a, b) and leaf level carbon balance represented by the difference between rates of photosynthesis and dark respiration $\left(\mathrm{A}_{\mathrm{sat}}-\mathrm{R}_{\mathrm{n}}\right.$; panel $\left.\mathrm{c}, \mathrm{d}\right)$ of cotton plants. Bars indicate mean value for each treatment combination and error bars represent standard error of mean $(n=5)$. Thermal regimes characterized by different daytime temperature (i.e. $32 / 22^{\circ} \mathrm{C}$ and $32 / 26^{\circ} \mathrm{C}$ ) are indicated by hatched bars. 


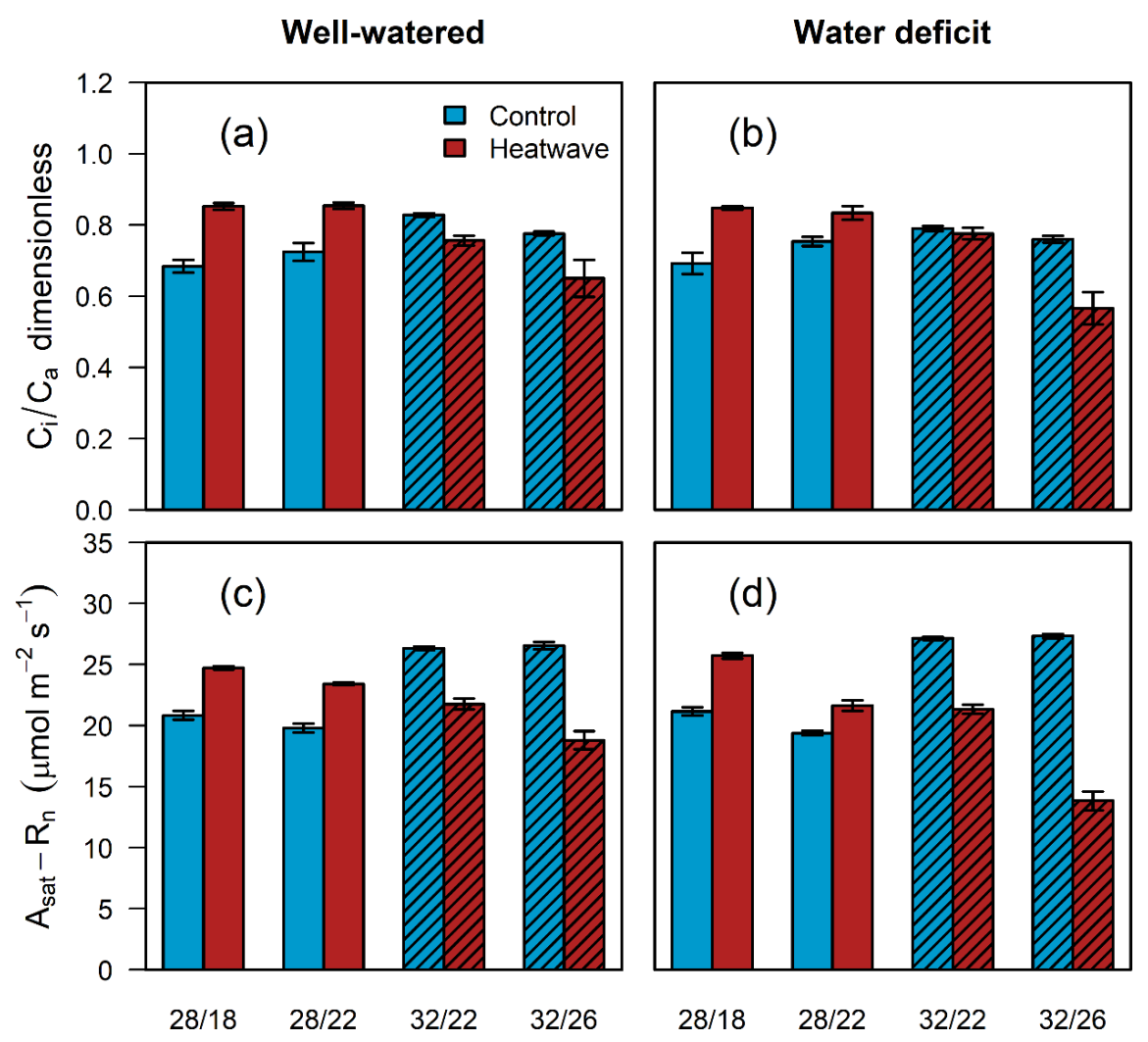

Figure 3 Response of leaf photosynthetic rate to leaf temperature for cotton plants grown under different temperature and water regimes. Solid line indicates fitted photosynthesis-temperature response curves using quadratic function and surrounding shaded bands indicate the corresponding $95 \%$ confidence interval $(\mathrm{n}=5)$. Note that the photosynthesis-temperature response curves for $32 / 22^{\circ} \mathrm{C}$ and $32 / 26^{\circ} \mathrm{C}$ treatments are overlapped in panel a.

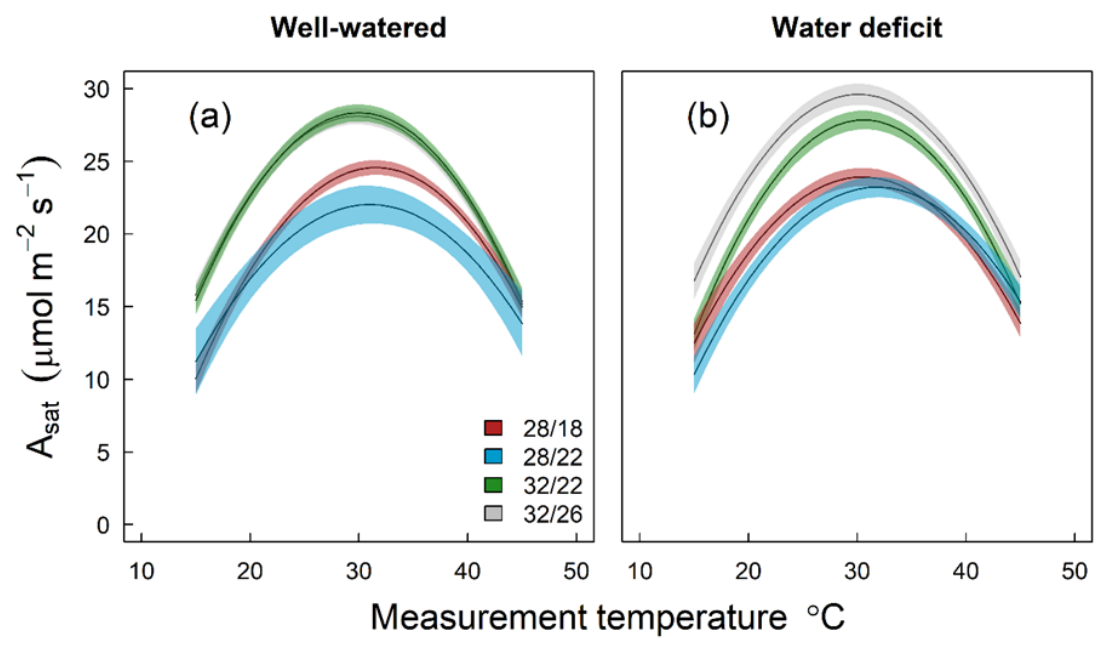




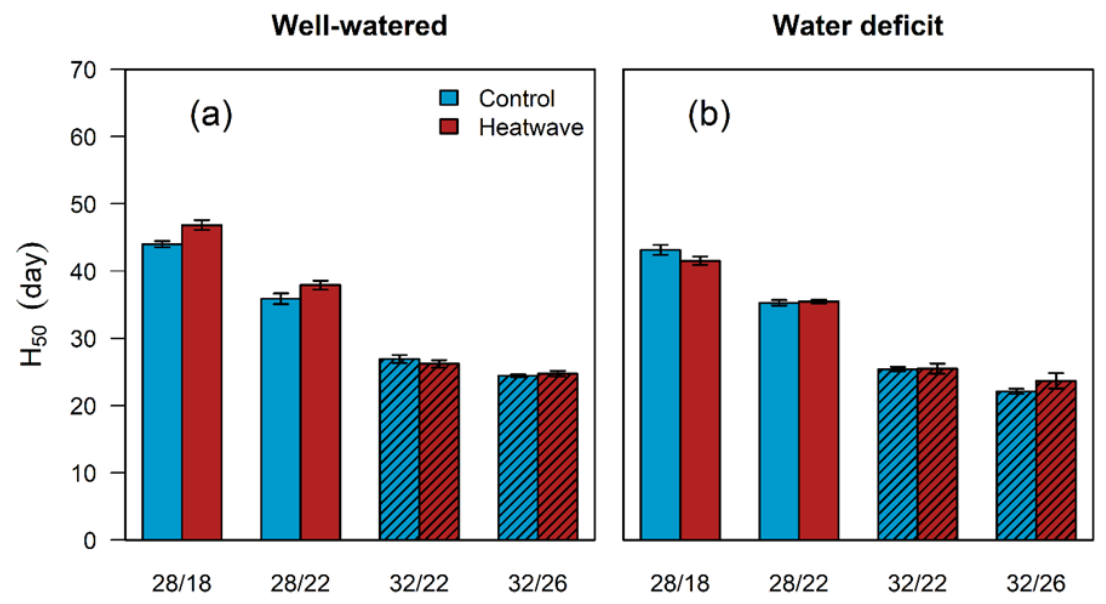

Figure 4 Growth rate (as defined by plant height) of cotton plants exposed to different growth temperature, water and heatwave treatments. Rate of growth is quantified by the days required for plant height to reach $50 \%$ of its maximum. Bars indicate mean value for each treatment combination and error bars represent standard error of mean $(\mathrm{n}=5)$. Thermal regimes characterized by different daytime temperature (i.e. $32 / 22^{\circ} \mathrm{C}$ and $32 / 26^{\circ} \mathrm{C}$ ) are indicated by hatched bars. 


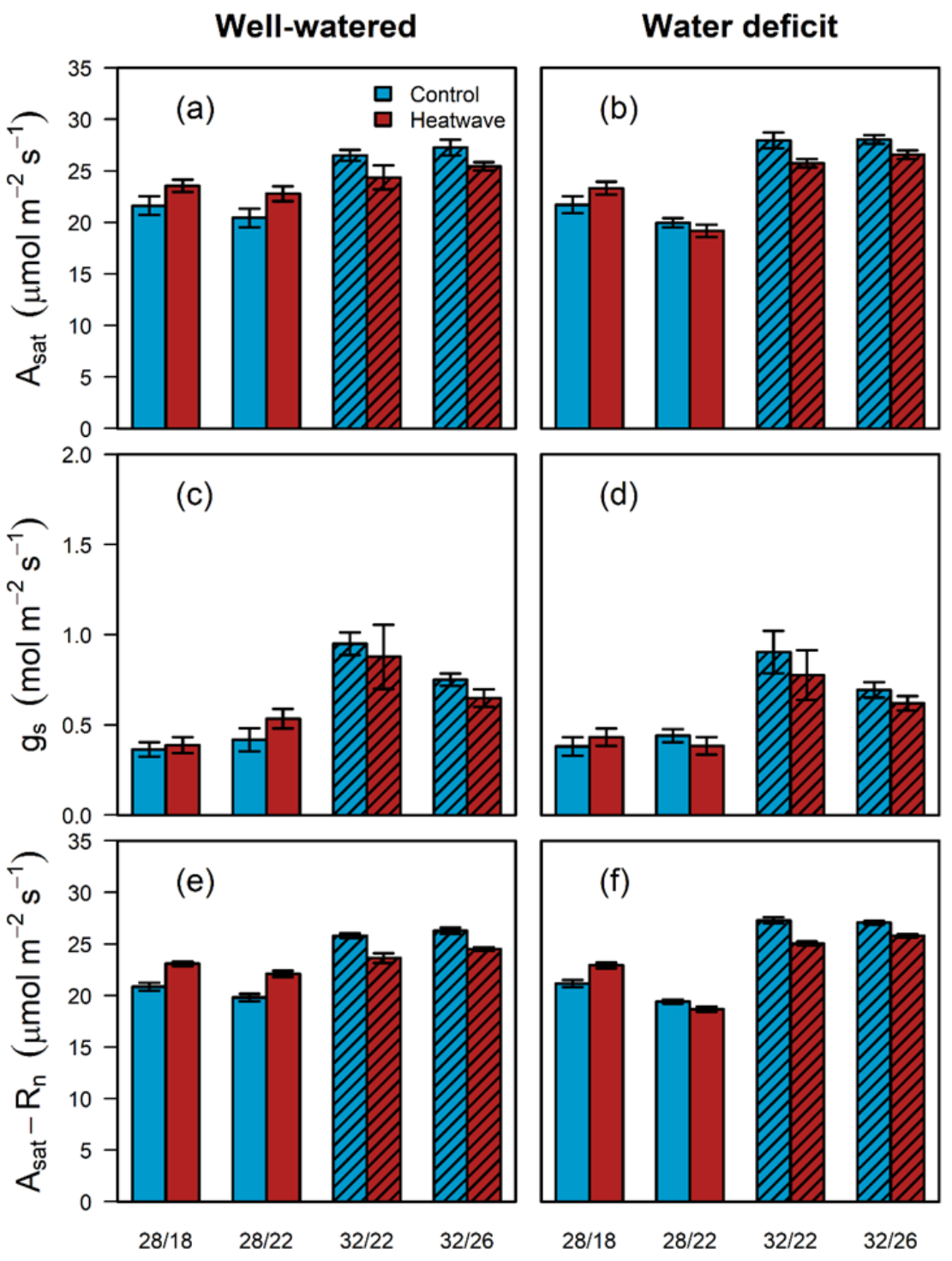

Figure 5 Recovery of leaf gas exchange variables following heatwave stress in cotton plants. Rates of light saturated photosynthesis $\left(\mathrm{A}_{\mathrm{sat}}\right.$; panel $\left.\mathrm{a}, \mathrm{b}\right)$, stomatal conductance $\left(\mathrm{g}_{\mathrm{s}}\right.$; panel $\left.\mathrm{c}, \mathrm{d}\right)$ and leaf carbon balance $\left(A_{\text {sat }}-R_{n}\right.$; panel e, f) were measured after plants were placed under their prevailing growth temperature for two days following the 5-day heatwave treatment. Bars indicate mean value for each treatment combination and error bars represent standard error of mean $(n=5)$. Thermal regimes characterized by different daytime temperature (i.e. $32 / 22^{\circ} \mathrm{C}$ and $32 / 26^{\circ} \mathrm{C}$ ) are indicated by hatched bars. 
Well-watered
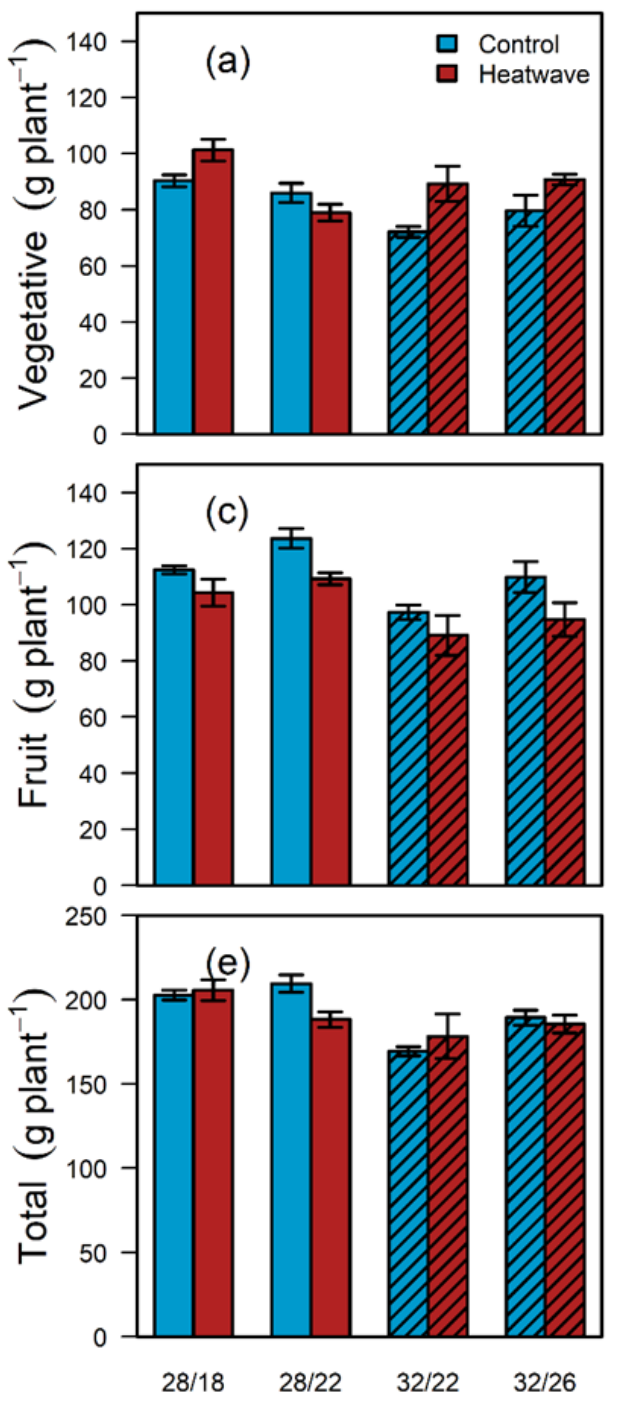

Water deficit

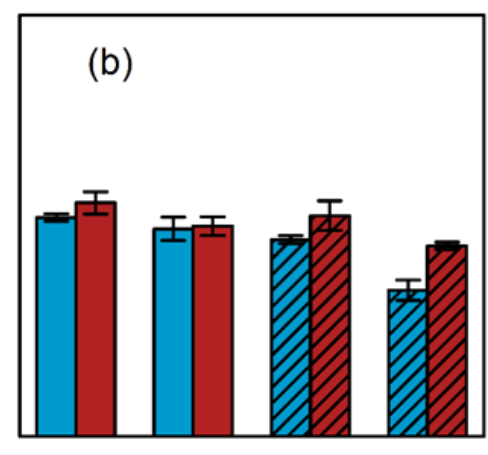

(d)

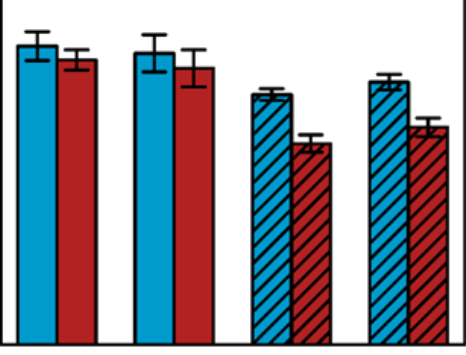

(f)

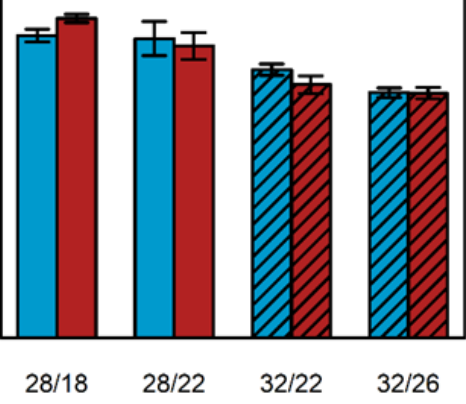

Figure 6 Effects of growth temperature, water regime and heatwave on vegetative dry mass (i.e. leaves, stems and branches; panel a, b), fruit dry mass (i.e. lint and bract; panel c, d) and total dry mass (panel $\mathrm{e}, \mathrm{f}$ ) of cotton plants at harvest at the end of the experiment. Bars indicate mean value for each treatment combination and error bars represent standard error of mean $(n=5)$. Thermal regimes characterized by different daytime temperature (i.e. $32 / 22^{\circ} \mathrm{C}$ and $32 / 26^{\circ} \mathrm{C}$ ) are indicated by hatched bars.

Table 1 Results of Two-way ANOVA showing the main and interactive effects of growth temperature (Temp) and water deficit stress (Water) on physiological variables and biomass productivity of cotton plants. Significant effect is considered when P[?]0.05 and is displayed in bold. Variables presented in the table are physiological parameters of net photosynthetic rate $\left(\mathrm{A}_{\mathrm{sat}}, \mu \mathrm{mol} \mathrm{m} \mathrm{m}^{-2} \mathrm{~s}^{-1}\right)$, stomatal conductance $\left(\mathrm{g}_{\mathrm{s}}, \mathrm{mol} \mathrm{m}^{-2}\right.$ $\left.\mathrm{s}^{-1}\right)$, dark respiration rate $\left(\mathrm{R}_{\mathrm{n}}, \mu \mathrm{mol} \mathrm{m} \mathrm{m}^{-2} \mathrm{~s}^{-1}\right)$, the ratio of intercellular to atmospheric $\mathrm{CO}_{2}\left(\mathrm{C}_{\mathrm{i}} / \mathrm{C}_{\mathrm{a}}\right)$ and leaf level carbon balance $\left(A_{s a t}-R_{n}, \mu m o l m^{-2} s^{-1}\right)$, and growth parameters of days required for plant height to 
reach $50 \%$ of its maximum $\left(\mathrm{H}_{50}\right.$, day), and dry mass $\left(\mathrm{g}\right.$ plant $\left.{ }^{-1}\right)$ for vegetative (leaves, stems and branches), fruit (lint and bract) and the total aboveground portion of the plant. Definitions, abbreviations and units also apply to other tables unless otherwise stated.

\begin{tabular}{llll}
\hline Variables & Treatment & & \\
\hline Physiology & Temp & Water & Temp $\times$ Water \\
$\mathrm{A}_{\text {sat }}$ & $<\mathbf{0 . 0 0 1}$ & 0.12 & 0.06 \\
$\mathrm{~g}_{\mathrm{s}}$ & $<\mathbf{0 . 0 0 1}$ & $<\mathbf{0 . 0 0 1}$ & $<\mathbf{0 . 0 0 1}$ \\
$\mathrm{R}_{\mathrm{n}}$ & $\mathbf{0 . 0 3}$ & $<\mathbf{0 . 0 0 1}$ & $\mathbf{< 0 . 0 1}$ \\
$\mathrm{C}_{\mathrm{i}} / \mathrm{C}_{\mathrm{a}}$ & $<\mathbf{0 . 0 0 1}$ & 0.40 & $<\mathbf{0 . 0 0 1}$ \\
$\mathrm{A}_{\text {sat }}-\mathrm{R}_{\mathrm{n}}$ & $<\mathbf{0 . 0 0 1}$ & 0.05 & 0.09 \\
$\mathrm{Growth}$ & & & \\
$\mathrm{H}_{50}$ & $<\mathbf{0 . 0 0 1}$ & $<\mathbf{0 . 0 1}$ & 0.37 \\
Vegetative mass & $<\mathbf{0 . 0 0 1}$ & $<\mathbf{0 . 0 0 1}$ & $<\mathbf{0 . 0 1}$ \\
Fruit mass & $<\mathbf{0 . 0 0 1}$ & $<\mathbf{0 . 0 0 1}$ & 0.30 \\
Total mass & $<\mathbf{0 . 0 0 1}$ & $<\mathbf{0 . 0 0 1}$ & $\mathbf{0 . 0 2}$ \\
\hline
\end{tabular}

Table 2 Optimum temperature $\left(\mathrm{T}_{\mathrm{opt}}\right)$ and light saturated photosynthetic rate at $\mathrm{T}_{\mathrm{opt}}\left(\mathrm{A}_{\mathrm{opt}}\right)$ of cotton plants across temperature (Temp) and water deficit (Water) treatments. Data are shown as mean \pm standard error of mean $(n=6)$. Also given are the P-values of two-way ANOVA showing the main and interactive effects of temperature and water availability on two parameters, with significant effects displayed in bold. Numbers differ in superscripts within the same column indicate statistical difference at P [?]0.05 level.

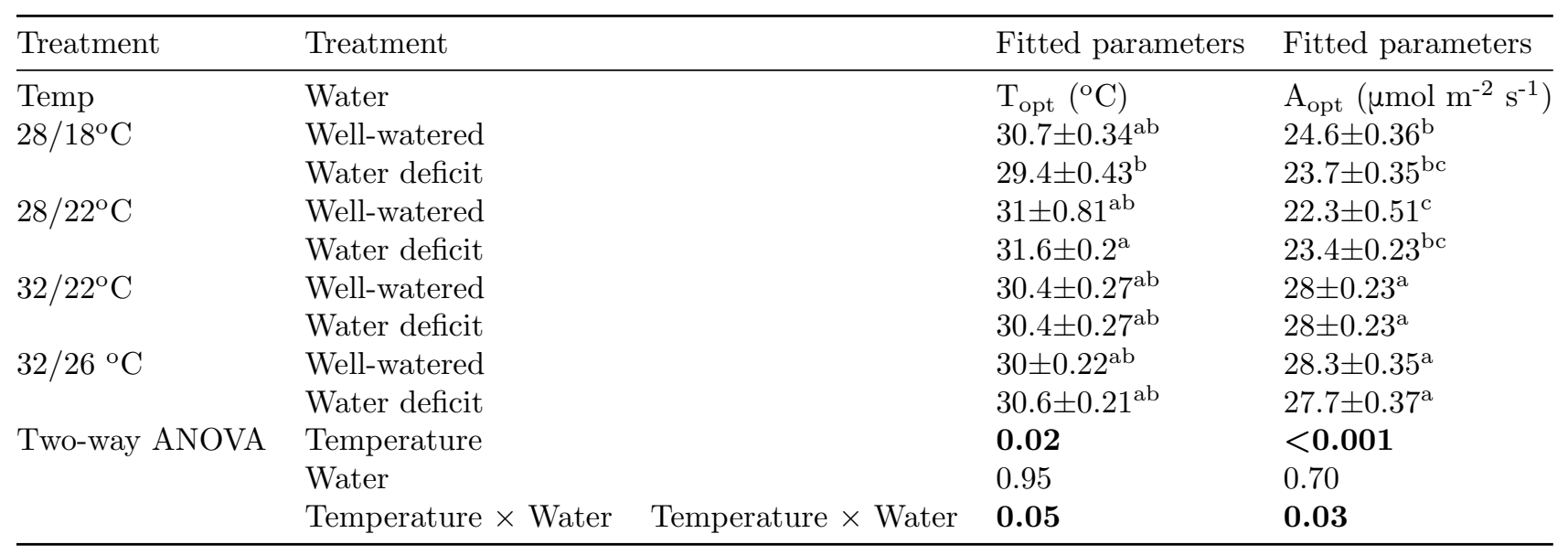

Table 3 Results of two-way ANOVA showing the main and interactive effects of nocturnal warming (NW) and water deficit stress (Water) on physiological variables and biomass productivity of cotton plants in cool (i.e. $28 / 18^{\circ} \mathrm{C}$ and $28 / 22^{\circ} \mathrm{C}$ ) and warm (i.e. $32 / 22^{\circ} \mathrm{C}$ and $32 / 26^{\circ} \mathrm{C}$ ) growth temperature regimes. Significant effect is considered when $\mathrm{P}$ [?]0.05 and is displayed in bold.

\begin{tabular}{lllll}
\hline Variables & Cool temperature regime & Cool temperature regime & Cool temperature regime & Warm temperature re \\
\hline Physiology & NW & Water & NW $\times$ Water & NW \\
$\mathrm{A}_{\text {sat }}$ & Physiology & & & \\
$\mathrm{R}_{\mathrm{n}}$ & $<\mathbf{0 . 0 1}$ & 0.92 & 0.64 & 0.60 \\
& 0.07 & 0.06 & 0.05 & 0.53
\end{tabular}




\begin{tabular}{lllll}
\hline Variables & Cool temperature regime & Cool temperature regime & Cool temperature regime & Warm temperature re \\
\hline $\mathrm{A}_{\text {sat }}-\mathrm{R}_{\mathrm{n}}$ & $<\mathbf{0 . 0 1}$ & 0.69 & 0.52 & 0.69 \\
Growth & & & & \\
Vegetative mass & 0.17 & $\mathbf{0 . 0 2}$ & 0.65 & 0.30 \\
Fruit mass & 0.36 & $\mathbf{0 . 0 4}$ & 0.61 & 0.20 \\
Total mass & 0.69 & $\mathbf{0 . 0 4}$ & 0.81 & 0.31 \\
\hline
\end{tabular}

Table 4 Results of three-way ANOVA showing the main and interactive effects of growth temperature (Temp), water deficit stress (Water) and heatwave on physiological variables during stress phase and two days after recovery, and on growth variables of cotton plants. Significant effect is considered when P [?]0.05 and is displayed in bold.

\begin{tabular}{|c|c|c|c|}
\hline Variables & Treatment & Treatment & Treatment \\
\hline & Temp & Water & Heatwave \\
\hline Physiology: Stress phase & Physiology: Stress phase & Physiology: Stress phase & Physiology: Stress phase \\
\hline $\mathrm{A}_{\text {sat }}$ & $<0.001$ & 0.15 & $<0.001$ \\
\hline $\mathrm{g}_{\mathrm{s}}$ & $<0.001$ & 0.05 & $<0.001$ \\
\hline $\mathrm{R}_{\mathrm{n}}$ & 0.54 & 0.04 & $<0.001$ \\
\hline $\mathrm{C}_{\mathrm{i}} / \mathrm{C}_{\mathrm{a}}$ & $<0.001$ & 0.25 & 0.16 \\
\hline $\mathrm{A}_{\mathrm{sat}}-\mathrm{R}_{\mathrm{n}}$ & 0.03 & $<0.01$ & $<0.001$ \\
\hline Physiology: Recovery phase & Physiology: Recovery phase & Physiology: Recovery phase & Physiology: Recovery phase \\
\hline $\mathrm{A}_{\text {sat }}$ & $<0.001$ & 0.84 & 0.35 \\
\hline $\mathrm{g}_{\mathrm{s}}$ & $<0.001$ & 0.33 & 0.44 \\
\hline $\mathrm{A}_{\mathrm{sat}}-\mathrm{R}_{\mathrm{n}}$ & $<0.001$ & 0.64 & 0.49 \\
\hline Growth & Growth & Growth & Growth \\
\hline $\mathrm{H}_{50}$ & $<0.001$ & $<0.001$ & 0.06 \\
\hline Vegetative mass & $<0.001$ & $<0.001$ & $<0.001$ \\
\hline Fruit mass & $<0.001$ & $<0.001$ & $<0.001$ \\
\hline Total mass & $<0.001$ & $<0.001$ & 0.48 \\
\hline
\end{tabular}

